\title{
¿Restaurar o renovar el arte contemporáneo?
}

\author{
MARIO PERNIOLA \\ Universidad de Roma
}

I. EL SIGLO XX, UN SIGLO DE RUINAS

LA LÓGICA VORAZ QUE LO HA SOSTENIDO TODO sobre los valores de novedad y de actualidad se somete y se resigna fácilmente ante la transitoriedad y la precariedad de las cosas y las vivencias humanas. La sabiduría popular italiana expresa este pensamiento con un proverbio: «es imposible tener la botella llena y a la mujer borracha». Desgraciadamente no todos recuerdan este proverbio. Por ejemplo, los coleccionistas de arte del siglo XX no parecen recordarlo, al observar con gran contrariedad que las obras de arte del siglo pasado fueron hechas con materiales muy poco perdurables que se deterioran pronto y de modo irreversible. Obras que bajo la excitación de las modas culturales y artísticas han sido adquiridas a un precio realmente muy alto si finalmente quedan transformadas en los próximos decenios en estado de ruina.

Un cuadro al óleo realizado según las reglas artísticas vigentes entre los siglos XV al XIX se conserva durante muchas generaciones y obtiene un valor estético y económico creciente con el paso del tiempo; eso es también debido a razones técnicas, como el lento asentamiento del material y la formación de una pátina que da a la obra mayor valor. Es a esta experiencia a la que se refiere la idea del «tiempo pintor», según la cual la obra gana una vida autónoma, independiente del acto creador, que le permite mejorarse a sí misma ${ }^{1}$.

Esta situación empezó a cambiar a inicios del siglo XIX, con la aparición de la producción industrial de los colores para pintura, los cuales son de una calidad muy inferior a los colores producidos artesanalmente en el taller del pintor. Pero en el transcurso del siglo XX la degradación técnica ha sufrido una aceleración impresionante no sólo a causa del uso de materiales nuevos (como colores acrílicos, barniz industriales, papel, elementos inestables y pocos compatibles con la incorporación de materiales orgánicos rápidamente deteriorables) que hacen imposible la aplicación de las reglas generalmente aceptadas por la

1 A. Conti, Manuale di restauro, Torino: Einaudi, 1996. 
restauración; incluso los pintores que han utilizados las técnicas tradicionales (como en el caso de los grandes frescos murales) tampoco han tenido la capacidad y la posibilidad práctica de producir obras que duraran siglos ${ }^{2}$.

Hoy nos encontramos ante una paradoja: un siglo, el veinte, que ha llevado al extremo la fiebre de la novedad y de la actualidad, se nos aparece como un cúmulo de ruinas de muy difícil restauración, a no ser que ésta se considere ocasionalmente imprescindible. El problema principal de la conservación y la restauración se nos presenta en términos muy diferente al modo en que ha sido teorizado por ejemplo por Cesare Brandy refiriéndose a las obras del pasado ${ }^{3}$. En efecto, el arte contemporáneo no implica sólo la producción de objetos diferentes de los del pasado. A partir del Romanticismo nos encontramos con un cambio más profundo y radical que afecta a la esencia misma del arte occidental, un cambio de la categoría cognoscitiva de lo que se entiende por «arte».

La figura del restaurador separada de la del artista nace al final del siglo XVIII, con la conversión en términos científicos de las prácticas artesanales. El perfil profesional del restaurador obtiene en aquel tiempo una completa autonomía respecto al del pintor y es beneficiado por un notable prestigio: se comienza a pensar que un buen restaurador es mejor que un mal artista ${ }^{4}$. No obstante, conviene partir del momento en el que las ideas del artista y del restaurador acerca de qué es el arte han tendido a diferenciarse. La perspectiva del restaurador y del conservador se centra en la obra que debe preservarse de la degradación provocada por el paso del tiempo, por la razón de daños casuales o intencionados causados por sucesos dramáticos. El artista, en cambio, comienza a ver en el arte algo más que un artefacto. Las acciones iconoclastas y vandálicas de la Revolución Francesa se centran en las estrechas relaciones entre creación y destrucción ${ }^{5}$; los filósofos del idealismo alemán atribuyeron al arte competencia, funciones y prerrogativas que van mucho más allá de una actividad manual limitada al complejo conocimiento técnico; finalmente, el desarrollo del capitalismo ha ofrecido a los artistas horizontes económicos mucho más amplios que aquellos que conocieron en las épocas de mecenazgo y en los encargos eclesiásticos y aristocráticos ${ }^{6}$. Cabría añadir a esto la premisa de la profunda divergencia entre lo que el público y el restaurador entienden por arte y el modo en que los artistas, filósofos y críticos piensan el arte.

2 P. Montorsi, Una teoria del restauro contemporaneo, en: Conservare l'arte contemporanea (ed. de L. Righi, Firenze: Nardini, 1992, pp. 9-48.

3 C. Brandi, Teoria del restauro, Torino: Einaudi, 1977 ( $\left.2^{\mathrm{a}} \mathrm{ed}.\right)$.

4 A. Conti, Storia del restauro e della conservazione delle opere d'arte, Milano, Electa, 1988.

5 D. Gamboni, The Destruction of Art. Iconoclasm and Vandalism since the French Revolution, London: Reaktion Books, 1997.

6 R. Williams, Culture and Society. 1780-1950, London: Chatto \& Windus, 1958. 
Hannah Arendt divide la actividad humana en tres dimensiones: trabajar, producir y actuar ${ }^{7}$. El arte pertenece evidentemente a la segunda dimensión, a la que corresponde la figura del homo faber, el productor de objetos no destinados al consumo sino a permanecer inalterables tanto como lo permitan los procesos naturales que pudieran alterarlos o deteriorarlos. Mientras el trabajo ha debido asegurarse lo necesario para la vida y es por esto que no tiene ni principio ni fin, la acción de producir tiene, en cambio, un inicio y un fin relacionados respectivamente con el arranque y el cumplimiento del artefacto. Producir es también esencialmente diferente del actuar, que es irreversible e imprevisible y que constituye el rasgo distintivo de la vida política. Esta distinción procede al menos del Romanticismo, cuando se origina la concepción de un arte integrador del actuar y del trabajar. En el Romanticismo nace también la idea de arte total $^{8}$, que está en concurrencia con la acción política, con el trabajo económico e incluso con el modo de producir que se ha empleado tradicionalmente. De ella han nacido una parapolítica, una paraeconomía y un paraarte.

\section{LA PARAPOLÍTICA ARTÍSTICA}

El arte se transforma en el Romanticismo en una casi-acción, diferente de la acción militar y de la acción política pero en analogía con éstas. El descubrimiento del aspecto estratégico de lo bello no es una novedad: se encuentran manifestaciones importantes en la poética del Barroco. Pero es con el Romanticismo cuando la condición del artista y del poeta como héroe alcanzan tan vasta difusión. La idea romántica, según la cual lo que de verdad importa es la acción artística, presenta estrechos vínculos con la revolución política: ésta ha desencadenado en el artista estímulos subjetivos venturosos y titánicos que lo han inducido a entrar en competición con las ideologías políticas, religiosas y sociales. Esto no quiere decir que el artista haya hecho suyo el arte de la política: sólo ha tomado de la política la pasión que ésta despierta ${ }^{9}$. Thomas Carlyle ha analizado muy bien la transformación del artista en héroe: él mismo se considera la luz espiritual de un mundo al que guiar o transformar ${ }^{10}$. El giro cultural romántico avanza en una dirección absolutamente diferente a la del giro renacentista: no centra su atención en la posesión de un saber (como en el caso de Leonardo), sino en la insurgencia de la acción. Esta es la razón

7 H. Arendt, The Human Condition, Chicago-London: University of Chicago Press, 1958.

8 J. Galard-J. Zugazagoitia (ed.), L'oeuvre d'art totale, Paris: Gallimard, 2003.

9 E. Burke, Reflections on the Revolution in France [1790].

10 T. Carlyle, On Heroes, Hero-Worship and the Heroic in History [1841]. 
característica de la polémica en la que se encuentran la academia del arte, que será considerada no sólo inútil para el florecimiento del arte, sino prejudicial, ya que obstruye y anula el espíritu creativo del genio artístico. La educación artística asume en el Romanticismo el aspecto de Meisterklasse, de una enseñanza fundada en una relación profunda y espiritual entre el maestro y el discípulo. Todavía en estos tiempos el objeto artístico es poco valorado: éste es en todo momento un producto finito y limitado con el que deberá confrontarse la infinita creatividad del artista, el cual puede permitirse tener en esta confrontación un acercamiento irónico. Esto introduce cambios en la estructura del saber (el cual asume con frecuencia el carácter de la revelación de una «verdad») y de la obra de arte (que deberá tender a su superación en una actividad espiritual o social más alta).

La vanguardia del siglo XX lleva a su consecuencia última el primado de la acción artística sobre el producto. Ella constituye una revuelta cultural de enorme relevancia y de la que no es posible el retorno. En efecto, en tal revuelta está implícito un reto extremadamente ambicioso dirigido a los hombres de acción tradicionales, los militares y los políticos: «La poesía -escribe Rimbaud-no llevará el ritmo de la acción: le irá por delante» ${ }^{11}$. La acción artística no podrá por tanto ser juzgada sobre la base de la realización objetual: las nociones tradicionales de éxito y fracaso son inadecuadas para el tratamiento de un actuar que posee esencialmente un valor simbólico de prefiguración y de anticipación.

Ya los románticos habían inaugurado una parapolítica, que fue ridiculizada por un verdadero teórico de la política como fue Carl Schmitt ${ }^{12}$ : éste ha acusado a los románticos de ser el acompañamiento parasitario de las tendencias realmente activas de la época. Schmitt ha tenido en cuenta un elemento importante para comprender la vanguardia: el hecho de que la acción artística es políticamente inclasificable e irrelevante, no por carecer de toma de posición política sino, al contrario, por la excesiva falta de auténtica decisión y de elección irreversible. Lo que para la historia política no será más que marginal y secundario, es sin embargo tomado por la historia del arte como algo decisivo e irrevocable. A partir de este momento, la teoría artística se articula sobre tres conceptos: el arte, el no-arte (el kitsch) y el anti-arte (aquellas acciones que intentan mostrar que la experiencia artística es una acción que transciende al producto artístico). Es sobre todo esta última dimensión, al representar el elemento de propulsión de los últimos treinta años del siglo veinte, la que introduce en el mundo del arte el aniconismo y la iconoclastia, junto al destruccionismo y el vandalismo.

¿Qué sentido tiene restaurar una obra que se autodestruye? Esta es la pregunta que se hace Heinz Althöfer, uno de los primeros en pensar los problemas

11 A. Rimbaud, Lettre au voyant (à Paul Demeny, 15 de mayo de 1871).

12 C. Schmitt, Politische Romantik, Berlin: Dunkler \& Humblot, 1919. 
de la restauración del arte contemporáneo ${ }^{13}$ : ejemplos no faltan, desde la máquina de Jean Tinguely, que se autodestruye, a la obra de chocolate de Dieter Roth. El recorrido que, desde el Romanticismo, ha conducido a esta situación extrema ha sido largo. Un momento decisivo está representado por Duchamp, con el que el arte entra en polémica consigo mismo. El arte contemporáneo se pone a sí mismo en cuestión, llevando a cabo una operación de desilusión y de desencanto, y burlándose de los valores artístico y estético del pasado. Sin embargo, según Baudrillard es una operación que fue hecha hace tiempo: ella está vinculada al nombre de Duchamp ${ }^{14}$. La desilusión tiene un carácter dramático, es un acontecimiento que muestra de una vez por todas la imposibilidad de tomar en serio el arte como acción. En el caso de Duchamp, el objeto artístico está en el punto de mira: él cumple una operación casi mágica, que consiste en transformar ciertas acciones en obras de arte. El mundo entero se convierte en un ready-made. Toda la estructura de la escena y de la representación queda abolida de un sólo golpe.

Una gran parte de la producción artística del siglo XX es un arte sin obra de arte, como lo ha definido con acierto Jean Galard ${ }^{15}$. La acción del arte no consiste ya en la fabricación de un artefacto que pueda identificarse como obra artística, sino en una acción, a veces ínfima: mover un objeto, cambiar la orientación, modificar un nombre. Ser artista se convierte en un especie de actitud para la acción que, sin embargo, resulta continuamente frustrada. Haciendo frente a un arte transformado en parapolítica, la intervención de la conservación deberá limitarse a su documentación.

A partir del momento en que el arte se reduce a ser una acción transgresora, éste entra en concurrencia con otro tipo de acción simbólica capaz de tener un impacto mediático mucho mayor. En el curso de los años sesenta el movimiento Internacional Situacionista lleva a su consecuencia extrema este postulado, alejándose progresivamente de toda pretensión artística y viendo en la revuelta social la continuación natural de Dadá y del Surrealismo ${ }^{16}$. Sucesos como el suicidio del escritor japonés Yukyo Mishima tienen un significado político absolutamente nulo, pero un impacto mediático muy fuerte ${ }^{17}$ : el llamado «incidente Mishima» puede considerarse una acción artística parapolítica. Lo mismo

13 H. Althöfer, Il restauro dell'arte moderna e contemporanea, en Conservare l'arte contemporanea, op. cit., pp. 75-81.

14 J. Baudrillard, Le complot de l'art, Paris: Sens \& Tonka, 1997, e Illusion, désillusion esthétiques, Paris, Sens \& Tonka, 1997.

15 J. Galard, L'art sens oeuvre, en: J. Galard-J. Zugazagoita (ed.), L'oeuvre d'art totale, op. cit., pp. 161-199.

16 M. Perniola, Los situacionistas, Madrid, Machado Libros, 2008.

17 F. Mazzei, Il suicidio rituale di Mishima, en Studi Filosofici, XXIX, 2001, Napoli: Istituto Universitario Orientale \&Bibliopolis, pp. 237-256. 
puede decirse de las revueltas estudiantiles y el terrorismo ${ }^{18}$. Esto explica la afirmación sorprendente y extremadamente cínica del músico alemán Karlheinz Stockhausen ante el atentado a las torres gemelas del 11 de septiembre, al decir que era «la obra de arte más grande del mundo» ${ }^{19}$. En esta afirmación se expresa plenamente la frustración y el sentido de fracaso del artista romántico, el cual no ha logrado hacer una sola acción verdaderamente importante.

Hoy los verdaderos enemigos del arte son aquellos que pretenden disolver la acción literaria y artística en «comunic-acción». No son capaces de producir ninguna acción que merezca ser recordada y representada.

\section{LA PARAECONOMIA ARTÍSTICA}

Hemos visto cómo el arte contemporáneo tiende a eliminar la distinción entre producir y actuar: el artista del acontecimiento se presenta como un hombre de acción. También la diferencia entre producir y trabajar se reduce notablemente: hacer arte queda absorbido por una lógica mercantil que reproduce los dispositivos y la mentalidad pertenecientes a la economía capitalista. El origen de este proceso está en el Romanticismo: artistas y escritores encuentran un público a quien vender sus obras: los productos artísticos adquieren ahora un valor económico completamente independiente del de los materiales con los que han sido hechos, del tiempo empleado para hacerlo y de la habilidad profesional del artífice. La producción del arte se distingue claramente de la producción manufacturada y asimila aspectos que pertenecen a la lógica del capitalismo industrial y financiero.

El escritor checo Karel Teige ha descrito muy bien el proceso que sigue la producción artística cuando se emancipa de sus vínculos corporativos: el artista gana una libertad total pero, a cambio, se convierte en un esclavo del mercado: el arte que ha conseguido independizarse del control de la iglesia, de la censura y de la organización corporativa termina siendo completamente dependiente del dinero ${ }^{20}$. La crítica se transforma en publicidad; el lugar del coleccionista ha sido ocupado por el especulador; la historia del arte se presta a los intereses de los museos; la firma decide el precio de la venta.

En el curso del siglo XX las perspectivas del artista y del restaurador divergen profundamente como es evidente en los considerados falsos de autor. La restauración es heredera de la idea de «original», de unicidad de la obra de arte: ¿Cómo juzgar a aquellos artistas que, como De Chirico, James Ensor o

18 W. R. Farrell, Blood and Rage, Toronto: Lexington Books, 1990.

19 «Frankfurter Allgemeine Zeitung», 18 de septiembre de 2001.

20 K. Teige, Jarmack umení [1935], tr. fr. Le marché de l'art, Paris: Allia, 2000. 
Duchamp, vuelven a hacer, por razones de enriquecimiento, obras que fueron célebres mucho antes?

El paso siguiente en la comercialización del arte se produce en los años sesenta: esto ocurre con el Pop Art y con el desplazamiento del mercado del arte de París a Nueva York. En este proceso, un momento de gran importancia es el protagonizado por Andy Warhol. Como dice Baudrillard, con él se cumple la comercialización de la totalidad del mundo simbólico considerado como nulidad ${ }^{21}$.

Con el Business Art, el arte pasa a ser publicidad de sí mismo. La diferencia entre el punto de vista del artista y el del restaurador es un abismo. Andy Warhol considera su estudio en Nueva York una Factory, una fábrica de obras de arte obtenidas mediante el reciclado de imágenes tomadas de los mass media según técnicas variadas y una intervención pictórica mínima. Muy a menudo la dimensión operativa y manual del arte es delegada -por expresa voluntad del artista- en otras personas: por ejemplo, las pinturas murales de Lewitt, o muchas intervenciones de Beuys y Christo, no son acabadas por ellos mismos, aunque sí se garantizan una especie de copyright sobre los productos resultantes de sus ideas. ¿Cómo se puede conservar o restaurar una idea? El arte contemporáneo el cual siempre tiene un aspecto conceptual, comienza a ser casi del todo inmaterial, como el dinero. No está equivocado otro artista americano, Jeff Koons, al reconocer que «el arte no consiste en hacer un cuadro, sino en venderlo».

Sin embargo, es del hiperproductivismo económico de donde provienen los mayores peligros. En efecto, la obra de arte tiende, como los vestidos y otras tantas mercancías, a ser asimilada por un proceso cada vez más rápido de fabricación y de destrucción: para aumentar la producción es preciso poner en el mercado cosas poco perdurables, de las que poder desprenderse fácilmente para dejar lugar a la novedad; de este modo, los tiempos del trabajo y del disfrute se contraen al máximo. Esta dinámica queda bien expresada en estas palabras de Beuys: «No hay nada que hacer con el arte, y esta es la única posibilidad de hacer alguna cosa con el arte» ${ }^{22}$. Los happening, las performances, las instalaciones y en general los efectos meramente comunicativos responden bien a esta exigencia. La tendencia a la «producción destructiva» se enfrenta a la aspiración de la obra de arte a ser transmitida a la posteridad y a constituir un bien de inversión «más perdurable que el bronce».

21 J. Baudrillard, Le crime parfait, Paris: Galilée, 1995, pp. 109-26.

22 Citado en P. Bürger, Theorie der Avantgarde, Frankfurt a M.: Suhrkamp, 1974. 


\section{EL PARAARTE FETICHISTA}

Hemos visto de qué manera el arte contemporáneo se proponía ser simultáneamente acción y trabajo, produciéndose así una parapolítica artística y una paraeconomía artística. No obstante, el arte contemporáneo sigue produciendo objetos. La atención de los conservadores y restauradores se dirige obviamente hacia estos objetos. Pero estos objetos no permiten que se les trate como si pertenecieran a la época dorada del arte occidental (del siglo XIV a las últimas décadas del siglo XVIII). También en el ámbito de la producción el Romanticismo representa una línea divisoria. La devaluación del artefacto se manifiesta en la poética del fragmento. La idea clásica de obra de arte nos remite a su perfección: el artista debe llevar a término su obra, a menos que circunstancias externas lo impidan. Frente a esto, el Romanticismo atribuye al fragmento una cierta autonomía. También en este aspecto la vanguardia del siglo XX lleva a sus consecuencias últimas el legado romántico: para Dadá, la obra no sólo es fragmentaria, sino incluso casual. El azar es, en efecto, uno de los principios de la poética y de la técnica dadaísta de Marcel Duchamp: como es sabido, la rotura accidental de su obra Gran vidrio pasa a formar parte esencial de ésta.

Como se ha dicho, una parte considerable del arte del siglo XX se ha orientado hacia la desmaterialización y la conceptualización (que encuentra su culminación en el Arte Conceptual). Junto a esta tendencia, cabría encontrar otra que anda en dirección contraria, esto es, hacia una exaltación de los materiales: se usan colores hasta ahora inéditos, se introducen en el arte todo tipo de materiales, desde los más resistentes (cemento, hierro, plomo...) a los más deteriorables (manteca, chocolate, queso...). Sin embargo, bien visto, las dos tendencias no son contradictorias entre sí. El punto de unión entre ambas es el culto al fetiche, la conversión al plano artístico de una patología religiosa, social y sicológica. Los casos límites de las obras del Eat art (como el ángel hecho de pan de especias o los enanos de chocolate) sólo pueden ser conservados mediante su inmersión en sustancias de conservación (por ejemplo, el plexiglás $)^{23}$. ¿Pero no se traiciona de este modo la intención del artista, el cual evidentemente ha querido que su obra sea deteriorable?

La totalidad del arte occidental del siglo veinte puede ser interpretada bajo la categoría del fetichismo. En efecto, como Marx mostró, el valor del fetiche no está en sus cualidades materiales, en sus características sensibles. Marx atribuye a la mercancía el carácter de fetiche, por coincidir en ella lo sensible y lo suprasensible, lo concreto y lo abstracto, del mismo modo que el arte del siglo veinte avanza a través de lo conceptual y lo material ${ }^{24}$.

23 H. Althöfer, loc. cit.

24 M. Perniola, El sex appeal de lo inorgánico, tr. de Mario Merlino, Madrid: Trama, 1998. 
Documentar la acción artística, mantener el valor económico de la empresa artística, preservar la obra entendida como fetiche: éstas parecen ser las funciones de la restauración de las obras de arte contemporáneas occidentales ${ }^{25}$. Pero esto es completamente independiente de su valor artístico ${ }^{26}$.

\section{OTRA CIVILIZACIÓN ARTÍSTICA CONTEMPORÁNEA: EL JAPÓN.}

Cuando observamos la producción artística japonesa de inspiración occidental (gendai bijustu) a la luz de los problemas que hemos considerado hasta aquí (y más específicamente las extensiones de la producción entre actuar y trabajar), el resultado es completamente diferente al occidental.

Consideremos la cuestión de la acción artística. También en Japón se asiste a partir de los años ochenta a una multiplicación de performances y de acciones anti-arte, pero -según Okabe Aomi- esta tendencia tiene un significado muy diferente, incluso opuesto, del que damos a acontecimientos similares en Occidente $^{27}$. Para los occidentales, el punto de partida es una protesta contra la censura cristiana y su negación del cuerpo: por lo tanto, estas acciones poseen un significado vital y espontáneo; éste se conforma como una protesta de la inmanencia, del cuerpo vivo contra la trascendencia y la espiritualidad. En Japón, en cambio, las acciones vanguardistas son acciones rituales que actualizan en clave contemporánea la ceremonia del té. Mientras en Occidente la acción es pensada como novedad respecto al pasado, en Japón predomina el aspecto repetitivo del ritual. No hay así ruptura con el pasado, sino coexistencia del presente y del pasado. Si en Occidente la acción artística por excelencia tendría la forma de la acción terrorista, en Japón estaría en el rito.

También en un segundo aspecto del arte contemporáneo, el relativo a la confusión entre producir y trabajar, entre arte y vida cotidiana, encontramos profundas diferencias entre la vanguardia occidental y la japonesa. En efecto, el equivalente japonés del Pop Art, la Monoha (Escuela del objeto), aparecida hacia el final de los años sesenta, se inspira en principios opuestos a los del Pop Art. Como observa Chiba Shigeo, lo característico del arte japonés no consiste en separar objetos del mundo y ambientes (como sí ocurre en el Pop Art): incluso cuando son convertidos en obra de arte los objetos no quedan

25 M. Perniola, El arte y su sombra, Madrid: Cátedra, 2002, y Contra la comunicación, Buenos Aires, Amorrortu, 2006.

26 M. Perniola, «Del arte como transgresión al arte como profesión», en Estudios Filosóficos, Instituto Superior de Filosofía de Valladolid, n 161 , enero-abril 2007.

27 A. Okabe, «Action et avant-garde», en Japon des avant gardes, Paris: Ed. du Centre Pompidou, 1986, pp. 349-363. 
separados del mundo, debiendo ser obras de arte radicadas en el mundo y en su ambiente original ${ }^{28}$. Dicho de otro modo, el artista japonés produce y considera la obra de arte como «mundo»: su función es mostrar la comprensión del mundo entero según un punto de vista artístico. Por esto, la confusión entre arte y trabajo conduce en Occidente a la dictadura de la publicidad, y en Japón la consecuencia es exactamente la contraria, la integración de todos los aspectos de la existencia en su impermanencia.

Por último, queda todavía un tercer aspecto entre los que habíamos considerado, el relativo a la conservación y restauración de las obras de arte. Occidente y Japón consideran el problema de modos radicalmente diferentes. Como habíamos visto, el punto de vista occidental nos lleva al fetichismo. Sin embargo, ya al inicio del siglo XX, el filósofo del arte japonés Takayama Chogyu se opone a la manera en que este problema ha sido analizado en Occidente: en su opinión, se le ha dado demasiada importancia al monumento como objeto material, mientras que la importancia debe estar en la preservación de su forma ${ }^{29}$. La teoría de Takayama se inspira en el santuario de Ise, que fue destruido y reconstruido con plena fidelidad (usando técnicas heredadas del pasado) en un lugar próximo. En 1993 ha sido reconstruido por $61^{\circ}$ vez. La madera del viejo santuario fue usada para reconstruir el torri o para enviarla a otros santuarios de Japón. En estos ritos (extremadamente costosos) la conservación y la innovación coinciden. Es por esto por lo que han podido ser considerados como la máxima expresión simbólica de una concepción del mundo que, por un lado, acepta la contingencia, la transitoriedad y precariedad de todas las cosas y, por otro, afirma una voluntad de renacimiento y de renovación que no se opone al pasado y a las tradiciones, sino que se los apropia. Éste es un estatuto contrario al de occidente, el cual es prisionero de la polaridad entre un inmovilismo conservador y una innovación destructora (en término filosóficos, entre metafísica y nihilismo). El proceso de modernización ha traído en Occidente aspectos simultáneamente preservantes y destructivos, que no sólo se expresan en el arte, sino también en manifestaciones de la vida política, social y cultural.

En el contexto de esta oposición entre modernidad occidental y modernidad japonesa se interpreta el nuevo 21 st Century Museum of Contemporary Art, de Kanazawa, que en su programa propone sustituir las tres $\mathrm{M}$ del modernismo del siglo XX (Man, Money, Materialisme) por tres C (Consciousness, Collective Intelligence, Co-existence).

28 S. Chiba, «Situation d'une période critique à la fin des années 60», en Idem, pp. 375379.

29 Ch. Market, «Le Japon moderne face à son patrimoine artistique, en Cipango. Cahiers d'études japonaises, n. hors-série, 2002, pp. 242-290. 
Termino con una consideración histórico-filológica ${ }^{30}$. En inglés, se utiliza la misma palabra (restoration) para indicar la restauración de la obra de arte y el hecho político que lleva al nacimiento del Japón moderno (Meiji Ishin, esto es, Meiji Restoration). La palabra inglesa Restoration (como la italiana restaurazione) tiene un significado político referido al desarrollo de la historia europea desde la primera mitad del siglo XIX, que la opone a revolution. Para los anglo-americanos, y en general para los occidentales, revolution-restoration forman una pareja de nociones opuestas entre sí. Pero el término japonés ishin no equivale ni a una ni a otra: revolution deberá decir kakumei (palabra adoptada por Fukuzawa Yukichi para indicar el inicio de la época Meiji), mientras restoration significa fukko (palabra no muy usada). De esto se deriva que la palabra ishin es muy difícil de traducir a una lengua occidental, porque indica un tipo de cambio que no encuentra su categoría en el pensamiento occidental. El estudioso italiano Alessandro Valota propone traducirla por rinnovamento: él observa que el joven samuraï (por ejemplo Sakamoto Ryôma), que es portador del ishin, adoptará la palabra isshin (con doble s), que acentúa el significado de ishin (con una sola s). Mientras en ishin el ideograma shin (nuevo) está precedido de $i c h i$ (uno), que implica totalidad, en ishin está precedido de $i$ (cuerda), que implica el legado, la continuidad con el pasado. En otras palabras, el gran cambio de 1868 no debe ser pensado como una restauración (Restoration) del pasado, y tampoco como una revolución radical (kakumei), sino como un rinnovamento, una categoría que en occidente no existe pero que explica el carácter específico y original de la modernidad japonesa, esencialmente diferente de la modernidad occidental. La conclusión es que en Japón existe un modo de pensar las relaciones entre el presente y el pasado en fuerte contraste con el modo occidental ${ }^{31}$. Este modo de pensar afecta no sólo al arte, sino también a la política y a la sociedad ${ }^{32}$.

Traducción de Alexandra Bouteaux

30 A. Valota, «La grande transformazione del Giappone Meiji», en E. COLLOTTI PISCHEL, Capire il Giappone, Milano, Franco Angeli, 1999, pp. 112-139.

31 S. KATO, Nihon bungakushi josetsu [1980]; tr. it. Storia della letteratura giapponese, Venezia, Marsilio Editori, 1996.

32 M. PERNIOLA, «La yuxtaposición japonesa», en Sibila, Sevilla, n 19, 2005, pp. 40-2. 